\title{
Papers
}

\section{Perceptions of open access publishing: interviews with journal authors}

Sara Schroter, Leanne Tite, Richard Smith

\begin{abstract}
Objective To explore authors' attitudes towards open access publishing and author charges, their perceptions of journals that charge authors, and whether they would be willing to submit to these journals.

Design Semistructured telephone interviews.

Participants 28 randomly selected international authors who submitted to the BMJ in 2003.

Results Authors were more aware of the concepts of open access publishing and author pays models than previously reported. Almost all authors supported the concept of open access, but few had submitted to an open access journal, other than the $B M J$. Reasons for not submitting included lack of awareness of which journals publish with open access, and journal quality taking a higher priority in decision making than the availability of open access. Authors disliked the idea of author charges without institutional support and were concerned about implications for authors from developing countries and those without research funding. However, many said they would probably continue to submit to journals they perceived as being of high quality even if they charged authors. Conclusions Authors consider perceived journal quality as more important than open access when deciding where to submit papers. New journals with open access may need to do more to reassure authors of the quality of their journals.
\end{abstract}

\section{Introduction}

The traditional business model in scientific journal publishing is based on subscription charges to readers. This model might restrict access to knowledge and generate undeserved profit for publishers. ${ }^{1-3}$ An emerging alternative is open access publishing, which gives lawful free access to journal content on the internet and is funded by means other than readers' subscriptions. Several models for financing this have been proposed, including an author pays model, where authors' contributions to the cost of publishing replace readers' subscriptions. The author's contribution is usually referred to as an "author charge," which might be paid by research funders or the author's institution. Some journals currently charging authors, such as BioMed Central journals, have made provision for institutional membership, which offers exemption from charges to individual authors. Currently, several biomedical publishers, including the BMJ Publishing Group, ${ }^{4}$ are considering moving towards open access funded through author charges, but we know little about authors' attitudes or likely responses to such charges. The evidence so far is limited to experiments with heavily subsidised author charges and several surveys of authors with limited sampling, ${ }^{5}$ low response rates ${ }^{6-7}$ and polls of authors from specialty journals about their preference for author charges or subscription models. $^{8}{ }^{9}$

Most journals experimenting with authors' fees charge less than Wellcome's estimated cost of $\$ 2500$ ( $£ 1329, € 1914)$ for producing an article. ${ }^{10}$ Consequently, these experiments cannot anticipate the long term sustainability of such a business model. To determine what motivates authors to publish in specific journals, whether they support open access publishing, and their perceptions of journals that charge authors fees, we carried out a series of interviews with authors to explore their understanding and attitudes.

\section{Methods}

\section{Sampling}

We divided the list of corresponding authors who submitted to the $B M J$ in 2003 into regions reflecting areas from which the $B M J$ receives most submissions: United Kingdom; North America; Australasia; and Europe (excluding United Kingdom). We used computer generated random numbers to select a sample of 10 authors from each region and a further 10 in the European sample for use in case of language difficulties.

\section{Data collection}

We conducted semistructured interviews by telephone (see bmj.com for interview schedule). Authors were asked if they were familiar with the terms "open access publishing" and "author pays models" and what they understood these terms to mean; whether they were in support of open access publishing; how they felt about the idea of author charges replacing subscription costs; whether they would consider submitting papers to author pays journals; and whether they would submit to the $B M J$ if it introduced publication charges.

We provided definitions to participants not familiar with the terms and to those who gave inadequate descriptions. We defined open access as "the provision of lawful free access to journal content online with its production funded by means other than subscription charges." An author pays model was defined as "an alternative method of funding journals whereby subscription charges are replaced with author charges for publication." When all interviews were completed, we independently collated responses and grouped the data according to emerging themes. ${ }^{11}$ Both interviewers (SS and LT) verified subsequent themes.

Fives more boxes of sample quotes and the interview schedule can be found on bmj.com 


\section{Results}

We attempted to contact 50 authors. Eleven were excluded (seven incorrect contact details, two absent, two language problems). Of the 29 eligible authors, 28 (72\%) took part.

The 28 authors, aged 31-60, lived in the United Kingdom (seven), United States (five), Canada (two), Australia (four), New Zealand (three), the Netherlands (two), Denmark (three), Germany (one), and Finland (one). Twenty one were men. Respondents had been active researchers for between two and 30 years; 18 had been active researchers for at least 10 years. Authors had published between zero and 305 articles, and 18 had published at least 25 papers. Over half (15) had published in at least 15 different journals. Most had received research grants. Participants had a wide range of research interests.

\section{Familiarity, support, and reservations}

All except four authors reported that they were familiar with the term "open access publishing" and defined it accurately when prompted. Some assumed open access meant publishing without peer review or printed journals. Half (14) reported that they had not previously submitted to an open access journal or were uncertain if they had. Only two had submitted a paper to an open access journal other than the $B M J$. Several said that it can be difficult to discern editorial policies for specific journals because libraries subscribe to e-journals which appear to be open access, while some journals have temporary open access to selected content.

Almost all authors supported the concept of open access publishing. Authors reported benefits for themselves and other researchers, including easier and faster literature searching; reduced costs in terms of time savings, photocopying, interlibrary loans, and subscriptions; faster dissemination of results to a wider audience; more equitable access; and the potential for medicine to improve globally.

Respondents were concerned that open access publishing might lead to vanity publishing (poor quality research being published for a fee) and a flood of non-peer reviewed papers on the internet. Peer review, they said, is extremely important and resources might be directed away from this to fund open access.

\section{Willingness to submit to open access journals}

Most authors were willing to submit to open access journals. Many said open access was not a relevant factor when they were selecting a journal. Some questioned the quality and reputation of existing open access journals.

\section{Familiarity with author pays model}

Twelve authors were not at all familiar with the term "author pays model." However, another 12 were either familiar with the term or had heard of the concept of journals charging authors fees to fund publication. Several had not made the connection between author charges and open access publishing. A further four authors reported being familiar with the term but failed to describe it accurately; one believed it to be vanity publishing and three described page charges. Only nine authors could name some existing author pays journals.

\section{Attitudes towards author charges}

Authors were mostly against author charges. Many thought there were negative implications of shifting costs to authors and that authors themselves should not be required to pay. Some thought charges might be acceptable if grant agencies and universities agreed to support authors. Some were concerned by the idea of paying to publish in non-peer reviewed journals and that the standard of publishing might decline. A few commented on the difficulty of implementing the model and the need for author charges to become standard so that the quality of journals could still be evaluated.

Several authors were concerned for those who could not afford to pay and said waivers would be necessary. Unfunded research, including methodological work, research done by junior doctors and $\mathrm{PhD}$ students, and researchers in developing countries, might not be published.

An author pays system might represent an additional barrier to researchers, resulting in restricted publications, which could have serious implications (box 1).

\section{Willingness to submit to author pays journals}

Overall, authors were not keen on the author pays model and would hesitate to submit to journals operating under such models. A few said charges might deter them and they would first look for journals that did not charge. Some said they would only submit to an author pays journal if all journals charged authors or if the better regarded journals they usually submit to switched to this model.

Factors of importance when selecting a journal included impact factor, reputation, readership, speed of publication, and the quality of peer review systems (box 2). Therefore, they would continue to submit appropriate papers to journals they regarded as "high quality" even if they charged. Mediating factors, however, were how much journals would charge and whether research funders would pay on the author's behalf. If fees were too high granting agencies (public funders and charities) might not be willing to pay.

Reasons cited for not previously submitting to author pays journals included lack of familiarity and perceptions that they are not widely read, that they don't have impact factors, have inferior peer review, and are not of high calibre (box 3).

\section{Discussion}

Authors were aware of the concepts of open access publishing and author pays journals. While nearly all authors supported the idea of open access publishing, few had knowingly submitted to an open access journal. Concern was expressed about implications of author charges for those who may not be able to pay. Many said they would probably continue to submit to journals they considered as high quality if they charged authors, but this would depend on price and whether they received financial support.

\section{Box 1: Additional barriers to researchers (sample quotes)}

\section{Might restrict publications}

I wouldn't want geniuses to be inhibited to publish as then I wouldn't have access to their work (U5)

But you don't want the barrier to be too high. If costs are too large it would skew the type of submissions received (AM8) I have some concerns ... It is hard enough finding published literature for Cochrane as it is. It is even harder to find unpublished stuff. If the model was costly enough to drive publications underground that would make Cochrane's work even more difficult (A8)

\section{Research process is hard enough}

I would hate that. It's awkward as a scientist to go through writing your manuscript, it's time consuming. Having to find the money would make it worse (E14) 


\section{Box 2: Other factors are important when selecting a journal (sample quotes)}

Charging policy would not influence choice of journal Yes ... it would not be prohibitive ... But I would think more about it before submitting. The quality of the target journal you are trying to get published in is more important than having to pay a fee or not. I have not factored in open access as a reason to or not to submit. If one journal came up ... of good quality ... or if a journal changed to this status ... it wouldn't at all influence my choice ... even if there was a payment to be made (AM7)

\section{Quality and reputation of journal}

I would be willing to consider it. But what I am more concerned about is the quality of the publication. I have access to funds through which I could pay to publish ... as long as the fee isn't too outrageous (AM10)

I would be quite unhappy about it. I guess if it was a really top journal [I would submit] ... but I would be really unhappy about it. Basically for quite a long time I would not be able to afford to do this (A7)

This comes back to the journals we target ... if they became open access journals our hands would be tied ... We would continue to target BMJ, Lancet, JAMA in the first instance ... this is standard with our unit and the work we do [trials]. If they became open access we would submit and pay grudgingly because they have a phenomenal reputation. There is huge motivation for researchers to pursue publications in journals with the highest impact factors. If open access had an effect on impact factors then we would move on in the long term but in the short term we would continue to target the same journals (A8)

\section{Depends on impact factor}

Yes ... but again it depends on impact factor because the university I work for has guidelines. We are discouraged from submitting to low impact journals ... there is a list of journals we can use. I think this is widespread, at least in top universities, particularly in the UK with the focus on the RAE [research assessment exercise] (A9)

I might. It has to do with the impact factor whether I am willing to pay. That [the impact factor] determines a lot (E14)

\section{Findings relative to other studies}

Previous surveys in this area have been methodologically weak. ${ }^{5-7}$ We achieved a good response rate and were able to assess understanding of both the terminology and the concepts behind open access and author pays publishing. Some authors were unfamiliar with the terminology but were familiar with the ideas. In contrast, previous surveys found limited understanding of open access models, which could be due to an assumed familiarity with the terminology. ${ }^{5-7}$ The $B M J$ is an open access (but not author pays) journal, and this might also explain some differences. One survey found respondents associated open access with good quality, well indexed electronic material, and half the authors would not pay author charges under any circumstances. ${ }^{7}$ In contrast, some of our authors questioned the quality of existing open access journals and were more concerned about perceived quality of journals than open access or author charges.

\section{Study limitations}

Our sample was limited to authors submitting to the $B M J$, where views may differ from those of other authors. However, we took a random sample of international authors, many of whom had published in many other journals so their opinions are probably representative.

\section{Box 3: Reasons for not having submitted to author pays} journals (sample quotes)

\section{Perceived as not widely read}

I would try the more traditional journals first with bigger readership. There is no point writing and getting published if no one reads it. I would submit to journals I know people read (U1)

\section{Lack of impact factors}

They are new journals and so we don't know their impact ratings, etc, yet. I would think about that side of things too (U10)

\section{Inferior peer review systems}

Not yet because I don't see them as having the same peer review impact as other journals. I would have to see their peer review comments and system to decide (U2)

\section{Not high calibre}

There are enough other journals of high calibre, I wouldn't go there [BioMed Central] (A4)

\section{Implications}

Several publishers are considering moving to open access and could therefore benefit from understanding authors' perceptions and concerns. Authors in this study reported journal quality was more important than open access when deciding where to submit. They said that initiatives such as the research assessment exercise have obliged authors to publish in journals with high impact factors. New open access journals with lower impact factors will need to do more to reassure authors of the quality of their peer review processes and impact.

Some open access journals, such as Documenta Mathematica and Journal of Insect Science, do not charge processing fees. Those considering author charges, however, need to recognise that there are problems with this model and that they may need to make special arrangements for dealing with unfunded research and submissions from developing countries.

\section{Future research}

This small descriptive study has identified a range of attitudes towards open access publishing. Participating authors said their responses depended on how much journals would charge and whether funders and institutions would pay. The next step is to determine the acceptability of various charging models to stake-

\section{What is already known on this topic}

Several publishers are considering the viability of adopting open access publishing models funded through "author charges," but little is known about how authors will respond to publication fees

\section{What this study adds}

Authors support the concept of open access, though few questioned had submitted to an open access journal

Authors did not know which journals publish with open access, and perceived journal quality was more important than open access when selecting journals to submit to

Authors disliked the idea of author charges without institutional support and concerns were expressed about implications for authors from developing countries and those working on non-funded research 
holders and to conduct a comprehensive economic analysis of these models before concluding which model is most suitable.

Contributors: RS initiated the study; SS and LT designed the study, interviewed the authors, and interpreted the data. All authors assisted in writing the paper. SS is guarantor.

Funding: BMJ Publishing Group's research budget.

Competing interests: All authors are or were employed by the BMJ Publishing Group. RS has now left the group and is employed by the British subsidiary of the UnitedHealth Group, a large US health and wellbeing company. He is also on the board of the Public Library of Science, an open access publisher. The $B M J$ is currently an open access journal and is considering whether to adopt author charges to fund the publication process. The researchers who conducted the interviews and analysed the data (SS and LT) do not have a financial interest in what the $B M J$ decides to do. Because members of the $B M J$ staff were involved in the conduct of this research and writing the paper, assessment and peer review have been carried out entirely by external advisors. No member of the $B M J$ staff has been involved in making the decision on the paper.

Ethical approval: This study was approved by the BMJ ethics committee.

1 Adam D. Scientists take on the publishers in an experiment to make research free for all. Guardian 2003 October 6.

2 Hopkins C. Healthy warning: this journal supports full text, tariff-free archives. Nature webdebates 2001. www.nature.com/nature/debates/e-access/Articles/hopkins.html (accessed 7 July 2004).

3 Eisen M, Brown P. Should the scientific literature be privately owned and controlled? Nature webdebates 2001. www.nature.com/nature/debates/e-access/Articles/ Eisen.htm (accessed 7 July 2004)
4 Delamothe T, Smith R. Open access publishing takes off: the dream is now achievable. BMJ 2004;328:1-3.

5 Pelizzari E. Academic staff use, perception and expectations about open-access archives. A surve of social science sector at Brescia University. http://eprints.rclis.org/archive/00000737 01/Academic_staff_perception_about_Open_archives.htm (accessed 7 July 2004).

6 JISC/OSI. Journal authors survey report. www.jisc.ac.uk/uploaded_documents/ JISCOAreport1.pdf (accessed 7 July 2004).

7 Rowlands I, Nicholas D, Huntingdon P. Scholarly communication in the digital environment: what do authors want? Findings of an international survey of author opinion: project report. London: Centre for Information Behaviour and Evaluation of Research, Departmen of Information Science, City University, 2004. http://ciber.soi.city.ac.uk./ciber-pareport.pdf (accessed 7 July 2004).

8 Richardson M, Saxby C. Experimenting with open access publishing. Nature 2004. www.nature.com/nature/focus/accessdebate/12.html (accessed 7 July 2004).

9 Cozzarelli NR, Fulton KR, Sullenberger DM. Results of a PNAS author survey on an open access option for publication. Proc Natl Acad Sci 2004;101:1111. www.pnas.org/ cgi/doi/10.1073/pnas.0307315101 (accessed 7 July 2004).

10 Costs and business models in scientific research publishing: a report commissioned by the Wellcome Trust. April 2004. ISBN 184129 051-3. www.wellcome.ac.uk/publications (accessed 7 July 2004).

11 Pope C, Ziebland S, Mays N. Qualitative research in health care: analysing qualitative data. BMJ 2000;320:114-6.

(Accepted 19 October 2004)

doi $10.1136 /$ bmj.38359.695220.82

BMJ Editorial Office, BMA House, London WC1 9JR

Sara Schroter senior researcher

Leanne Tite research assistant

Richard Smith editor

Correspondence to: S Schroter sschroter@bmj.com 